\title{
The Simple Synthesis of High Metal Loading Single-Atom Catalysts via Chelate Fixation
}

\author{
Abolfazl Shakouri ${ }^{\dagger}$, Horie Adabi Firouzjaie ${ }^{\dagger}$, Karakalos G. Stavros, William E. Mustain, John R. \\ Regalbuto*, Christopher T. Williams* \\ Department of Chemical Engineering, University of South Carolina; Columbia, SC 29208, \\ USA. \\ *Corresponding authors. Email: regalbuj@cec.sc.edu and willia84@cec.sc.edu
}

\begin{abstract}
Supported atomically dispersed metal catalysts are at the frontier of catalysis research, promising combined advantages of well-defined sites and high selectivity, with high stability and easy separation characterizing solid catalysts. We report that addition of an organic chelating agent in the final stage of impregnation, allows the metal precursor to be anchored and isolated without the need for anchoring sites on the support. The resulting isolated atoms are characterized with scanning transmission electron microscopy, X-ray photoelectron spectroscopy, and thermal desorption of carbon monoxide. This "chelate fixation" (CheFi) method can yield relatively high loadings of single atoms (e.g., Pt, $\mathrm{Ru}, \mathrm{Ir}$ ), up to at least 1 atom $\mathrm{nm}^{-2}$ on a variety of carbon (e.g., black, activated carbon, diamond) and oxide (e.g., $\mathrm{TiO}_{2}, \mathrm{SiO}_{2}$ ) supports.
\end{abstract}

\section{One-Sentence Summary:}

20 A simple, novel synthesis method yields isolated atoms without the need for anchoring sites on the support. 
Supported single-atom catalysts (SACs) are at the frontier of catalysis research, promising the combined advantages of homogeneous (e.g., well-defined site, high selectivity) and heterogeneous (e.g., high stability, easy separation) catalysts (1-7). Such well-defined materials have the potential to provide unique catalytic performance due to the intimate electronic interaction between the isolated active site and a given support material, which serves as a ligand. Some examples of such materials include a $2 \mathrm{wt} \% \mathrm{Pt} \mathrm{SAC}$ for preferential oxidation of $\mathrm{CO}$ in hydrogen-rich fuel (8), a highly active, selective, and coke-resistant Rh single-atom catalyst dispersed in $\mathrm{Cu}$ for low-temperature, nonoxidative propane dehydrogenation $(9,10)$, and a stable heterogeneous single-atom Pd catalyst supported on graphitic carbon nitride for Suzuki coupling (11). A general limitation in these studies has been the inability to produce loadings of accessible single atoms that are relevant to industrial applications (12). In addition, in order to produce and retain isolated single metal atom sites in the resulting materials, novel and/or complicated synthesis methods have been employed (13-22). To fully exploit the potential for commercial applications of SACs, the development of scalable and facile synthesis methods that can produce high loadings of isolated active sites is required.

There are many synthetic methods available to deliver metal precursors to catalytic supports (i.e., oxides, carbon). For example, strong electrostatic adsorption (SEA), ensures an even distribution of metal ions on the support surface through control of solution $\mathrm{pH}(23-26)$. This method can reliably produce small metal nanoparticles $(27,28)$, as well as isolated single atoms if the metal loading is low enough $(29,30)$. However, at loadings greater than $\sim 0.1 \mathrm{wt} \%$, activation of such catalysts (i.e, through calcination and/or reduction treatments) results in cluster and nanoparticle formation $(29,31)$. One strategy to achieve high single metal atom loadings involves the use of chelating agents that complex with the metal precursor and are then pyrolyzed (sometimes along with other organic components) to produce a carbon material with single metal atoms dispersed throughout. However, there are some concerns that not all of the single atoms in such a carbon support matrix are accessible $(1,32)$, and the approach is limited to carbon. Another strategy is to employ supports with anchoring sites and to carefully tune the treatment protocols to maintain isolation, as has recently been demonstrated by Perez-Ramirez and co-workers (33).

Promising results have been reported using non-aqueous organic solvents to deliver metal salt and organometallic precursors to carbon support surfaces. Hutchings and co-workers (34) were able to achieve isolated $\mathrm{Au}, \mathrm{Pt}, \mathrm{Pd}$ and $\mathrm{Ru}$ up to a loading of $1 \mathrm{wt} \%$, and demonstrated their activity for acetylene hydrochlorination. More recently, Gates and co-workers achieved isolated Ir sites for $14.8 \mathrm{wt} \% \mathrm{Ir} / \mathrm{rGA}$ which were effective for ethylene hydrogenation (35). Due to the instability of the employed precursors in aqueous solution, "extra dry" organic solvents and air exclusion technique were employed $(34,35)$. Indeed, solution removal at the last step of the incipient wetness impregnation (i.e., before catalyst activation) has been reported to form crystallites because of weak interactions and redistribution of precursors ions $(36,37)$. Even for SEA, incomplete drying of the adsorbed precursors on the support during activation (Fig. S1) results in the formation of large nanoparticles.

We hypothesized that formation of reduced metal clusters and particles (as opposed to isolated atoms), even when starting with well-dispersed, adsorbed precursors obtained with SEA, is significantly influenced by the presence of water (Fig. 1A). In addition to any bulk water that might remain in support pores even after drying, there is also a significant amount of water associated with each precursor in the form of a hydration sheath $(38,39)$. For example, $\mathrm{PtCl}_{6}{ }^{2-}$ is known to retain one hydration sheath, while $\mathrm{Pt}\left(\mathrm{NH}_{3}\right)_{4}{ }^{2+}$ is known to retain two hydration sheaths, upon drying at room temperature. In order to retard (or eliminate) the negative influence of such 
water on the formation of supported single atoms, a chelating agent was introduced immediately following the precursor adsorption step. This chelating agent, 8-hydroxyquinoline (8-HQ), has a high affinity for transition metals (40-43), and has been shown to adsorb on a variety of oxide and carbon surfaces for applications in metal extraction (44-46). We surmised that 8-HQ, which is not soluble in water, will isolate the metal precursor on the support surface without the need for defects or anchoring sites (Fig. 1B). The strong metal-8-HQ interaction coupled and high normal boiling point of 8 -HQ $\left(267^{\circ} \mathrm{C}\right)$, would then allow the metal ion to be reduced with $\mathrm{H}_{2}$, while avoiding formation of clusters or nanoparticles. A comparison of SEA with this new chelate fixation (CheFi) method for Pt on $\mathrm{VXC}-72$ and $\mathrm{TiO}_{2}$ support substrates is provided in Fig. S2. It can be seen that there is significant particle/cluster formation for the SEA samples upon reduction in $\mathrm{H}_{2}$ at $300^{\circ} \mathrm{C}$, albeit with a very tight particle size distributions (Figs. S2B,D). However, the CheFi samples (Figs. S2A,C), primarily consist of isolated single atoms, along with a few agglomerates as dimers, trimers, etc. It was further found that SEA was not necessary for the CheFi method to be successful. A set of experiments conducted for VXC-72 at $\mathrm{pH} 2.9$ (where maximum SEA of the Pt precursor occurs) and 9 (the point of zero charge where there is no SEA) shows identical results (Figs. S3A-B). In addition, contrary to SEA, the CheFi synthesis method proved successful at high ionic strength using both anionic and cationic Pt precursors (Figs. S3C-D). Because the chelating agent is not soluble in water, a polar solvent like acetone with a higher dipole moment than water is needed to dissolve the chelating agent prior to its addition to the impregnating solution.

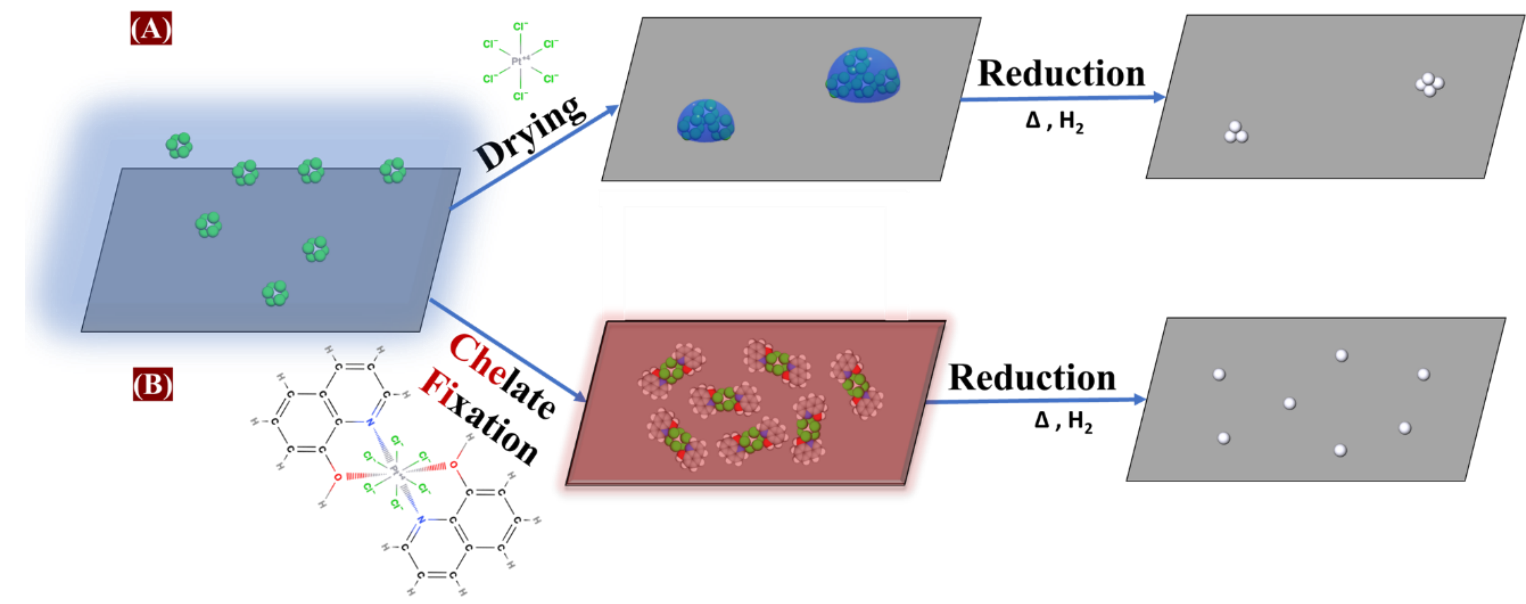

Fig.1. Schematic of hypothesis and synthesis methods, (A) effect of water during drying and activation of the catalyst, $(B)$ chelate fixation during drying and activation. Chemical formulas and structures (based on van der Waals spheres) prepared using tools available at https://molview.org/.

In this contribution, we demonstrate that this proposed CheFi method produces high densities (up to at least $\sim 1$ atom $/ \mathrm{nm}^{2}$ ) of isolated single atoms of $\mathrm{Pt}$, Ir, and $\mathrm{Ru}$ on a variety of carbon (e.g., black, activated carbon, diamond) and oxide (e.g., $\mathrm{TiO}_{2}, \mathrm{SiO}_{2}$ ) supports with no anchoring sites. The results open up a simple, cheap and scalable method to produce SACs, for both fundamental catalysis studies and practical industrial applications.

Aberration corrected scanning transmission electron microscopy (STEM) has been used to characterize the samples. Fig. 2A-F show the images of CheFi-prepared $0.8 \% \mathrm{Pt} / \mathrm{VXC}-72$, $3.5 \% \mathrm{Pt} / \mathrm{VXC}-72$, and 7.7\%Pt/VXC-72 corresponding to densities of $0.1,0.45$ and $1.0 \mathrm{atom} / \mathrm{nm}^{2}$. With a reduction temperature of $170^{\circ} \mathrm{C}$ the atoms are seen to be completely isolated (Figs. 2A- 
C), while a higher reduction at $300^{\circ} \mathrm{C}$ maintains isolation (Figs. 2D,E), except for a small amount of agglomeration at the highest metal loading (Fig. 2F). Dispersing 1 atom $/ \mathrm{nm}^{2}$ on a Norit ROX activated carbon with a surface area of $\sim 1200 \mathrm{~m}^{2} / \mathrm{g}$ resulted in $30 \% \mathrm{Pt} / \mathrm{C}$ SACs shown in Fig. 2G-H. The higher resolution images show well distributed single atoms. The higher temperature reduction $\left(300^{\circ} \mathrm{C}\right)$ again causes a small amount of Pt-Pt coordination (Fig. $\left.2 \mathbf{H}\right)$. The highest magnifications contain overlapping images of well-defined single atoms at the focal plane and blurry atoms off the focal plane. Fig. S4 shows the same area of sample with either the left-hand side (Fig. S4A) or right-hand side (Fig. S4B) in focus. Atoms are clearly resolved when any section of the sample is brought into focus. Such imaging strongly suggests that the metal atoms are not only present on the outer support surface, but within the support pore framework.

Further characterization has been performed with X-ray photoelectron spectroscopy (XPS) and temperature programmed desorption of carbon monoxide (CO-TPD). The XPS measurement of $\mathrm{Pt} 4 \mathrm{f}$ peaks of $2 \% \mathrm{Pt} / \mathrm{VXC}-72$ prepared by standard dry impregnation after in-situ reduction in hydrogen, is shown in Fig. 3A. After reduction at $300^{\circ} \mathrm{C}$ only one peak at $71.2 \mathrm{eV}$ is observed, and is associated with the $\mathrm{Pt} 4 \mathrm{f}$ of metallic Pt nanoparticles (47). Indeed, reduction of the sample to $600^{\circ} \mathrm{C}$ resulted in the same position of the $\mathrm{Pt} 4 \mathrm{f}$ peak, confirming it as a reference for $\mathrm{Pt}$ nanoparticles. A 2\% Pt/VXC-72 catalyst prepared using CheFi was subjected to in-situ reduction at $170^{\circ} \mathrm{C}, 300^{\circ} \mathrm{C}$, and $600^{\circ} \mathrm{C}\left(\right.$ Fig. 3B). After reduction at $170^{\circ} \mathrm{C}$, a Pt $4 \mathrm{f}$ peak showed up at the characteristic position of $72.4 \mathrm{eV}$ for ionic $\mathrm{Pt}_{1}$, attributed to single atoms (48), which is consistent with the associated STEM images (Fig. S5A). A small peak at $70.9 \mathrm{eV}$ is attributed to formation of single atom Pt carbide atoms (49). The sample reduced at $300^{\circ} \mathrm{C}$, demonstrated two $\mathrm{Pt} 4 \mathrm{f}$ peaks at both $72.4 \mathrm{eV}$ and 71.2, indicating the presence of both ionic $\mathrm{Pt}_{1}$ atoms and neutral $\mathrm{Pt}_{1}$ atoms. Some of the neutral $\mathrm{Pt}$ atoms might be taking part in the formation of small nanoparticles, consistent once again with the associated STEM images (Fig. S5B). The 30\% $\mathrm{Pt} / \mathrm{C}_{\text {Norit }}$ catalyst reduced at $100^{\circ} \mathrm{C}$ (Fig. 3C) resulted only in the characteristic $\mathrm{Pt}$ 4f peak for ionic $\mathrm{Pt}_{1}$ at $72.4 \mathrm{eV}$, attributed to single atoms. Reduction at $170^{\circ} \mathrm{C}$ led in the formation of mostly neutral $\mathrm{Pt}_{1}$, as indicated by the $71.1 \mathrm{eV}$ peak (Fig. 3C). A higher reduction at $300^{\circ} \mathrm{C}$ again resulted mainly in neutral $\mathrm{Pt}_{1}$ atoms (Fig. 3C). Although, the $\mathrm{Pt}_{1}$ neutral state at $71.1 \mathrm{eV}$ can be attributed to nps or Pt clusters, the STEM images (Figs. 2G, 2H) clearly show that after reduction at $170^{\circ} \mathrm{C}-300^{\circ} \mathrm{C}$, the main feature on the surface is still $\mathrm{Pt}_{1}$ single atoms. The CO-TPD spectra (described later) from the same samples (Fig. 3F), also indicate that the majority of Pt is not in the form of nanoparticles.

Computational studies (50) of Pt single atoms and dimers on carbon help to explain how ionic $\mathrm{Pt}_{1}$, corresponding to single atoms, can become more electron rich and detected as neutral $\mathrm{Pt}_{1}$ on carbon. The DFT-calculated density of states of Pt single atoms predicts that hydrogen adsorption on defect sites and other oxygen containing surface functionalities, results in the appearance of Pt d-band energy levels closer to the Fermi edge. This is consistent with the conductive nature of single atom $\mathrm{Pt}$ after in-situ reduction, as there is evidence from the $\mathrm{O} 1 \mathrm{~s}$ $(\mathrm{OH}$ peak contributions Fig. 3D) that hydrogen is added on the substrate surface. A strong indication that the above prediction plays a major role in the current measurements, is also the fact that the effect of Pt neutralization upon reduction, is more evident on the defect-rich Norit ROX than on VXC-72. There are also predictions in the literature (51) which show that when Pt single atoms react with the carbon substrate, making stronger and shorter $\mathrm{Pt}-\mathrm{C}$ bonds, the $\mathrm{Pt}$ charge increases. There is some evidence of stronger Pt-C interaction after reduction at $170 \mathrm{C}$ (Figs. 3B, 3C) through the formation of small amounts of carbides. 

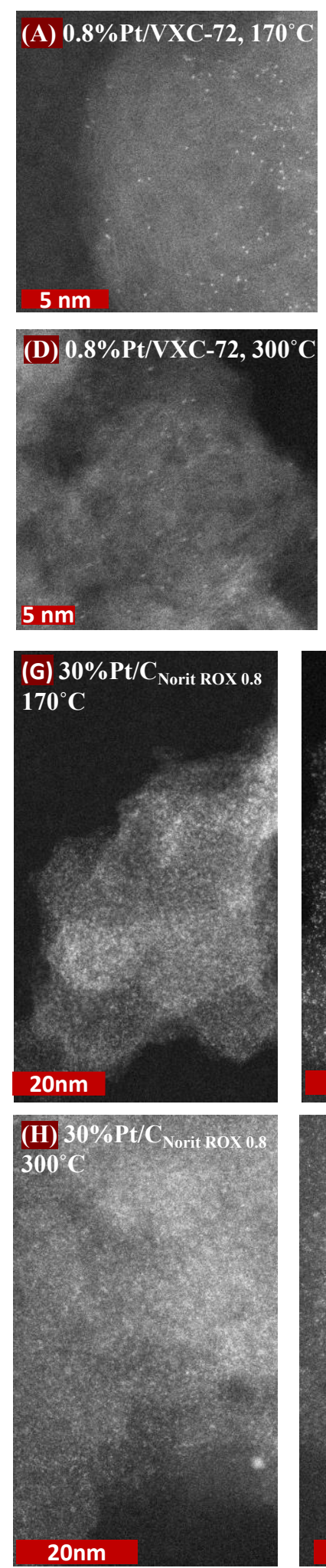
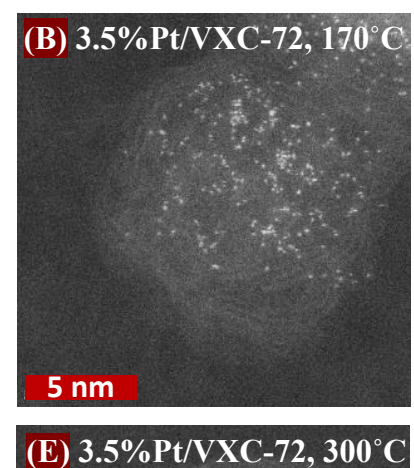

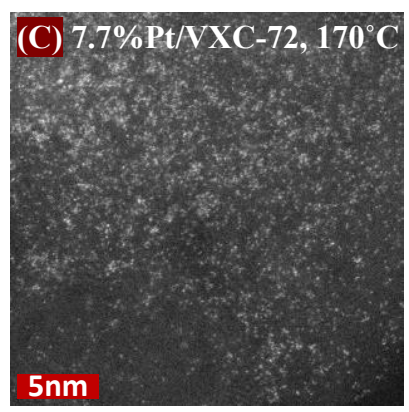

(F) $7.7 \% \mathrm{Pt} / \mathrm{VXC}-72,300^{\circ} \mathrm{C}$

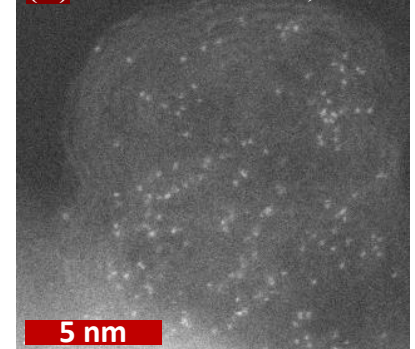

$5 \mathrm{~nm}$
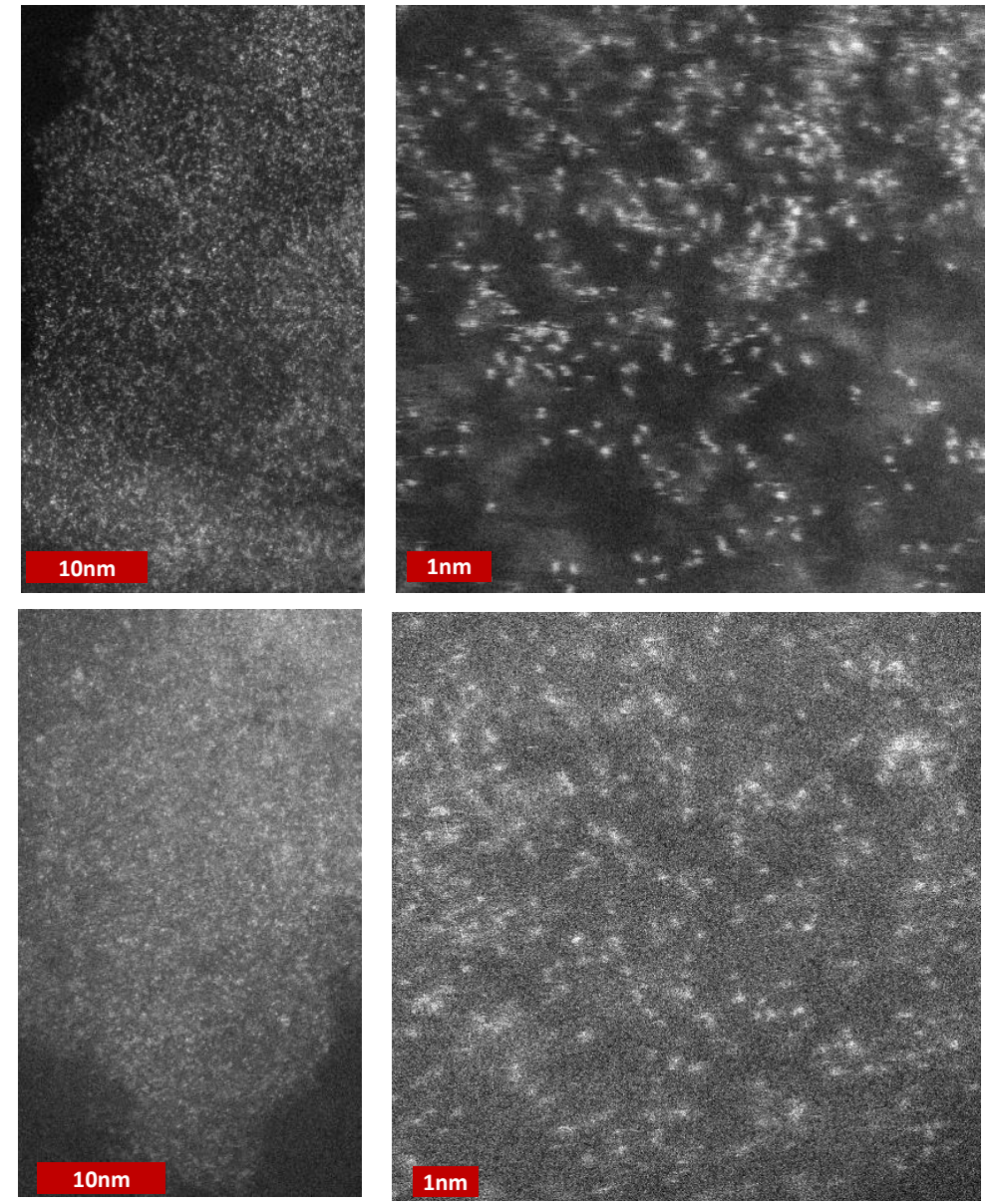

Fig.2. Various densities of single atom supported catalysts. STEM images of $0.8 \% P t / V X C-72$ CheFi, 3.5\% Pt/VXC-72 CheFi, 7.7\%Pt/VXC-72 (1 Pt atom/nm ${ }^{2}$ ) CheFi reduced at (A-C) $170^{\circ} \mathrm{C}$, and $(D-F) 300^{\circ} \mathrm{C}, 30 \% P t / C_{\text {Norit }}\left(1\right.$ Pt atom/nm $\left.{ }^{2}\right)$ CheFi-reduced at $(G) 170^{\circ} \mathrm{C}$, and $(\mathrm{H}) 300^{\circ} \mathrm{C}$. 
However, the effect of neutralizing the ionic $\mathrm{Pt}_{1}$ atoms is in a larger extent, which indicates that the addition of hydrogen on defects and carbon functionalities is the main reason for this observation. Computational studies (50) of Pt single atoms and dimers on carbon help to explain how ionic $\mathrm{Pt}_{1}$, corresponding to single atoms, can become more electron rich and detected as neutral $\mathrm{Pt}_{1}$ on carbon. The DFT-calculated density of states of Pt single atoms predicts that hydrogen adsorption on defect sites and other oxygen containing surface functionalities, results in the appearance of Pt d-band energy levels closer to the Fermi edge. This is consistent with the conductive nature of single atom $\mathrm{Pt}$ after in-situ reduction, as there is evidence from the $\mathrm{O} 1 \mathrm{~s}$ (OH peak contributions Fig. 3D) that hydrogen is added on the substrate surface. A strong indication that the above prediction plays a major role in the current measurements, is also the fact that the effect of Pt neutralization upon reduction, is more evident on the defect-rich Norit $\mathrm{ROX}$ than on VXC-72. There are also predictions in the literature (51) which show that when $\mathrm{Pt}$ single atoms react with the carbon substrate, making stronger and shorter $\mathrm{Pt}-\mathrm{C}$ bonds, the $\mathrm{Pt}$ charge increases. There is some evidence of stronger Pt-C interaction after reduction at $170 \mathrm{C}$ (Figs. 3B, 3C) through the formation of small amounts of carbides. However, the effect of neutralizing the ionic $\mathrm{Pt}_{1}$ atoms is in a larger extent, which indicates that the addition of hydrogen on defects and carbon functionalities is the main reason for this observation.

The CO-TPD can further distinguish between SACs and catalysts containing nanoparticles, as it used here as a probe molecule that provides information about adsorption sites and energies (52). The results in Fig. 3E demonstrate the difference in $\mathrm{CO}$ desorption temperature from completely isolated SACs and nanoparticles. The sample from which the top (red) curve is obtained, contains only nanoparticles (Figs. 3A and S6). The bottom (black) curve shows the CO desorption profile from the $2 \% \mathrm{Pt} / \mathrm{VXC}-72$ catalyst that was first reduced at $170^{\circ} \mathrm{C}$. A main $\mathrm{CO}$ desorption peak appears at $75^{\circ} \mathrm{C}$, and is attributed to desorption from single $\mathrm{Pt}$ atoms (47). A small shoulder at $130^{\circ} \mathrm{C}$ can be attributed to the Pt carbide in the catalyst(47), consistent with the XPS results (49). The middle (blue) curve shows the $\mathrm{CO}$ desorption profile for the $2 \% \mathrm{Pt} / \mathrm{VXC}$ 72 catalyst reduced at $300^{\circ} \mathrm{C}$. Desorption peaks observed at $75^{\circ} \mathrm{C}$ and $205^{\circ} \mathrm{C}$ can be attributed to single atoms and nanoparticles, respectively. These observations are consistent with the STEM images of the catalyst treated at $170^{\circ} \mathrm{C}$ (Fig. S5A) and $300^{\circ} \mathrm{C}$ (Fig. S5B) the latter of which is a 30 combination of isolated atoms and nanoparticles. The lower integrated area of the CO desorption peak is consistent with the loss of adsorption sites due to the formation of nanoparticles.

CO-TPD from the reduced $30 \% \mathrm{Pt} / \mathrm{C}_{\text {Norit }}$ sample, shows the wide range of adsorption sites with different binding strengths, indicating that this catalyst will be effective in a wide range of reactions and catalytic processes. Fig. 3F (blue) gives the CO-TPD pattern of that sample

35 reduced at $100{ }^{\circ} \mathrm{C}$. This sample is imaged in Fig. $\mathbf{S 7}$ and shows only isolated atoms. The COTPD pattern of this sample exhibits the peaks at $75^{\circ} \mathrm{C}$ and $130^{\circ} \mathrm{C}$ indicative of isolated atoms (atoms and $\mathrm{Pt}_{1}$ carbide). Further reduction at $170^{\circ} \mathrm{C}$ resulted in $\mathrm{CO}$ desorption at a wide range of temperatures (Fig. 3F dark green), expanding from $75 \mathrm{C}$ to almost $300 \mathrm{C}$. These spectra indicate stronger interaction of the $\mathrm{CO}$ with the Pt atoms, which becomes even more pronounced after 40 reduction at $300^{\circ} \mathrm{C}$. The above-mentioned observations exclude the possibility of nanoparticle formation after reduction, because in that case there would be only a distinct $\mathrm{CO}$ desorption at $\sim 220 \mathrm{C}$ characteristic of $\mathrm{CO}$ adsorbed on nanoparticles. On the contrary the CO-TPD confirms predictions from DFT (50) that the changes in the Pt d-band center due to the addition of hydrogen on defects and surface functionalities, affects the binding strength of the $\mathrm{CO}$ adsorption on Pt single atoms and dimers. TPD observations are consistent with the associated STEM images in Fig. 2H which clearly show that there are no nanoparticles on the catalyst after 
reduction (a total of 25 separate areas of the $30 \mathrm{wt} \% \mathrm{Pt} / \mathrm{C}_{\text {Norit }}$ were imaged, and none contained even a single nanoparticle). Finally, following the $\mathrm{N}$ 1s peak intensity in XPS (not shown here), we detected that as the reduction temperature increases, the chelating agent is removed, leaving Pt single atoms on the support with a wide variety of adsorption sites available to act as reaction active centers.
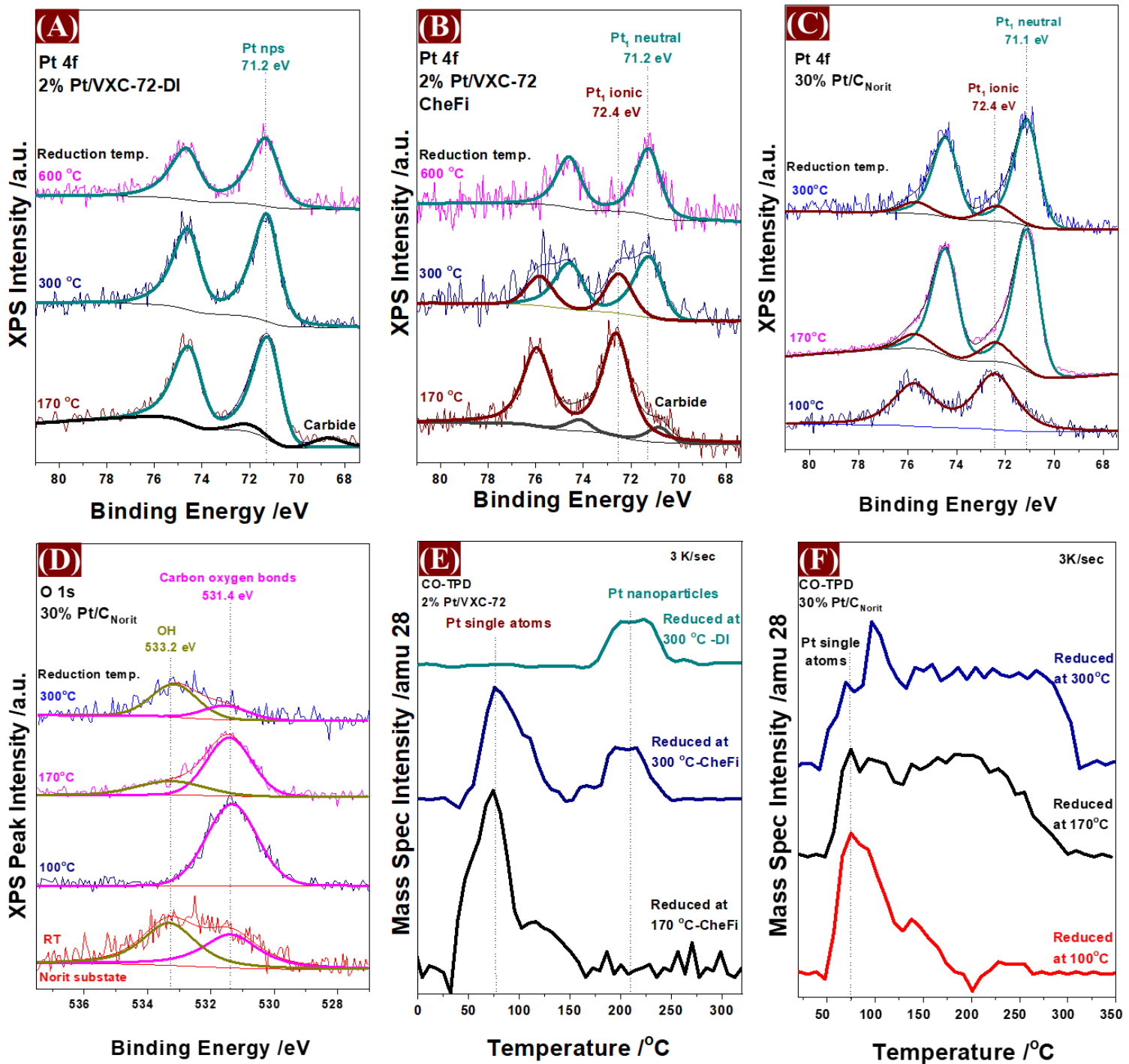

Fig.3. In Situ XPS studies and CO TPD, In situ XPS spectra of (A) Pt 4f fresh, reduced at $170^{\circ} \mathrm{C}, 300^{\circ} \mathrm{C}$, and $600^{\circ} \mathrm{C} 2 \% \mathrm{Pt} / \mathrm{VXC}-72 \mathrm{DI},(\mathrm{B}) \mathrm{Pt}$ ff fresh, reduced at $170^{\circ} \mathrm{C}, 300^{\circ} \mathrm{C}$, and $600^{\circ} \mathrm{C}$ $2 \% \mathrm{Pt} / \mathrm{VXC}-72 \mathrm{CheFi},(\mathrm{C}) \mathrm{Pt} 4 \mathrm{f}$ fresh, reduced at $100^{\circ} \mathrm{C}, 170^{\circ} \mathrm{C}$, and $300^{\circ} \mathrm{C} 30 \% \mathrm{Pt} / \mathrm{C} \mathrm{CheFi}$, (D) $O$ is fresh, reduced at $100^{\circ} \mathrm{C}, 170^{\circ} \mathrm{C}$, and $300^{\circ} \mathrm{C} 30 \% \mathrm{Pt} / \mathrm{C} \mathrm{CheFi}$, (E) CO-TPD of $2 \% \mathrm{Pt} / \mathrm{VXC}-72$ DI in situ reduced at $300^{\circ} \mathrm{C}$ and CheFi in situ reduced at $170^{\circ} \mathrm{C}$ and $300^{\circ} \mathrm{C}$, (F) CO-TPD of $30 \% \mathrm{Pt} / \mathrm{C}$ CheFi in situ reduced at $100{ }^{\circ} \mathrm{C}, 170^{\circ} \mathrm{C}$ and $300^{\circ} \mathrm{C}$.

The CheFi method appears to be very versatile with respect to both supports and metals. This is perhaps not surprising, given that 8 -HQ is well-known to chelate metal ions $(41,45,53)$ or metal ion complexes with ligands (54-56). As noted previously, 8-HQ has been shown to adsorb on a variety of typical support surfaces $(45,46)$. In addition to VXC-72 (i.e., carbon black) and Norit ROX (activated carbon), Figures 4A and B show representative STEM images for Pt on 
nanodiamond prepared with nitrate and chloride precursors, respectively. The result shows that single Pt atoms can be produced on a carbon support that has no surface functional groups. Silica (Fig. 4C and Fig. S8) and titania (Fig. 4D) are two other common industrial oxide support substrates for which CheFi also yielded isolated Pt atoms. Finally, Figures 4E and 4F show isolated metal atoms in 3.5\% Ir and $1.8 \% \mathrm{Ru}$ on VXC-72 prepared by the CheFi method.
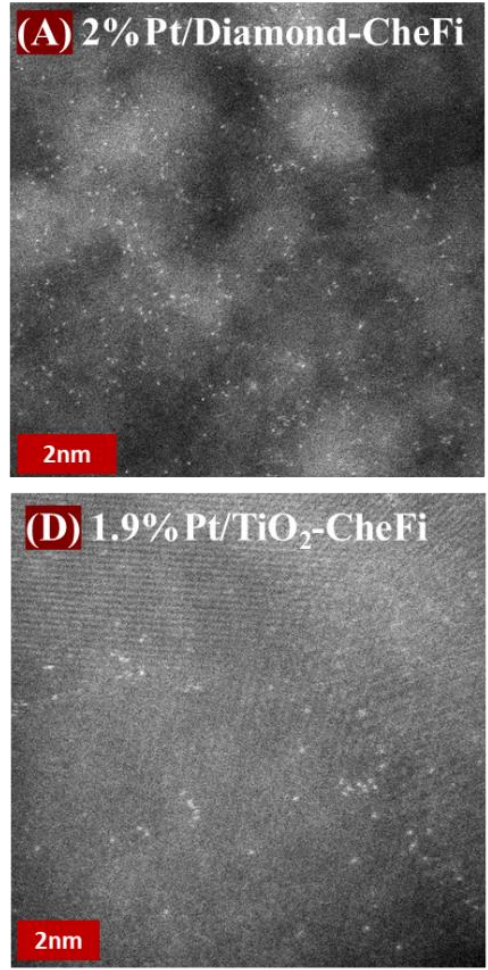
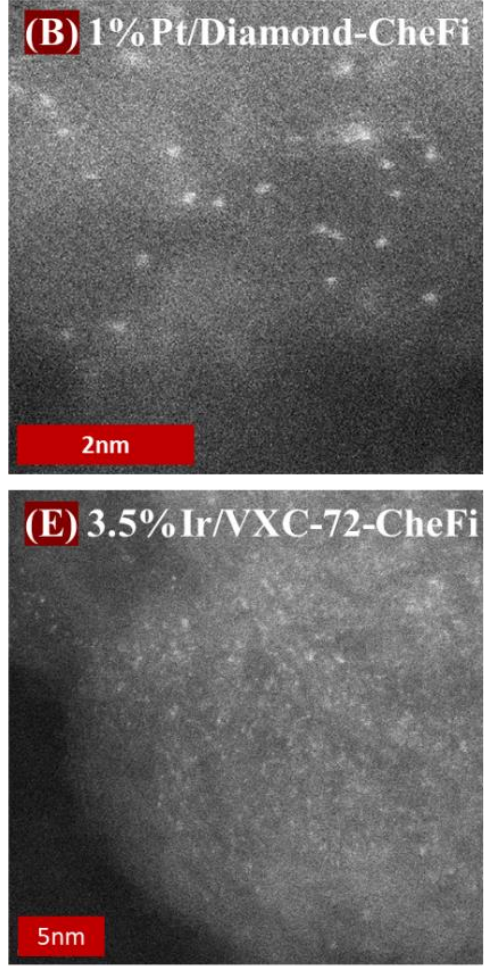
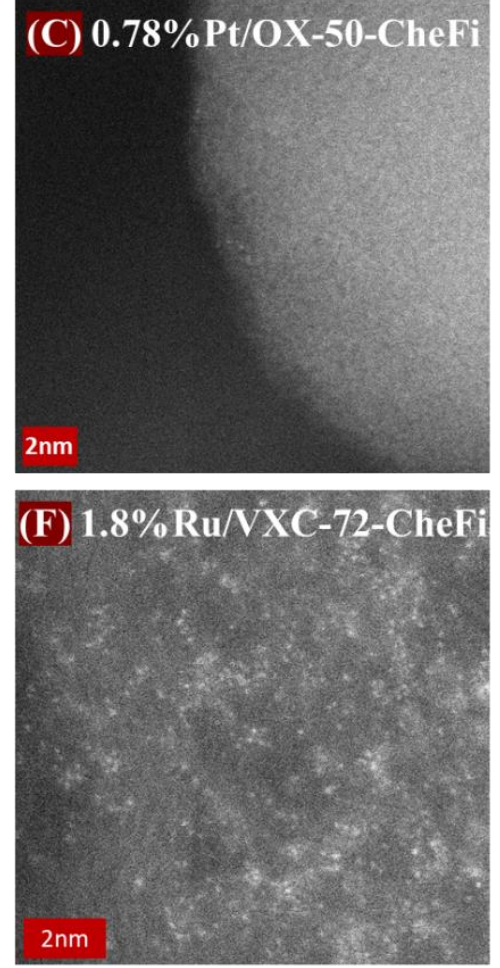

Fig. 4. Versatility of the CheFi method. (A) 2\% Pt/Diamond (nitrate precursor), (B) $1 \%$ Pt/Diamond (chloride precursor), (C) $0.78 \% \mathrm{Pt}_{\mathrm{SiO}}$, (D) $1.9 \% \mathrm{Pt} / \mathrm{TiO}$, $3.5 \% \mathrm{Ir} / \mathrm{VXC}$-72, and $1.8 \% R u / V X C-72$.

This facile, inexpensive method which does not rely on anchoring sites should be generalizable to many metal precursors and supports to prepare SACs at high metal loading.

\section{References and Notes}

1. S. K. Kaiser, Z. Chen, D. Faust Akl, S. Mitchell, J. Pérez-Ramírez, Single-Atom Catalysts across the Periodic Table. Chem. Rev. (2020), doi:10.1021/acs.chemrev.0c00576.

2. A. K. Datye, H. Guo, Single atom catalysis poised to transition from an academic curiosity to an industrially relevant technology. Nat. Commun. 12, 895 (2021).

3. M. K. Samantaray, V. D’Elia, E. Pump, L. Falivene, M. Harb, S. Ould Chikh, L. Cavallo, J.-M. Basset, The Comparison between Single Atom Catalysis and Surface Organometallic Catalysis. Chem. Rev. 120, 734-813 (2020).

4. J. Zhang, H. Yang, B. Liu, Coordination Engineering of Single-Atom Catalysts for the Oxygen Reduction Reaction: A Review. Adv. Energy Mater. 11, 2002473 (2021).

5. B. Singh, V. Sharma, R. P. Gaikwad, P. Fornasiero, R. Zbořil, M. B. Gawande, SingleAtom Catalysts: A Sustainable Pathway for the Advanced Catalytic Applications. Small. 
17, 2006473 (2021).

6. K. Qi, M. Chhowalla, D. Voiry, Single atom is not alone: Metal-support interactions in single-atom catalysis. Mater. Today. 40, 173-192 (2020).

7. S. Mitchell, J. Pérez-Ramírez, Single atom catalysis: a decade of stunning progress and the promise for a bright future. Nat. Commun. 11, 4302 (2020).

8. S. Cao, Y. Zhao, S. Lee, S. Yang, J. Liu, G. Giannakakis, M. Li, M. Ouyang, D. Wang, E. C. H. Sykes, M. Flytzani-Stephanopoulos, High-loading single Pt atom sites [Pt$\mathrm{O}(\mathrm{OH}) \& \mathrm{lt} ; \mathrm{em} \& \mathrm{gt} ; \& \mathrm{lt} ; \mathrm{sub} \& \mathrm{gt} ; \mathrm{x} \& \mathrm{lt} ; / \mathrm{sub} \& \mathrm{gt} ; \& \mathrm{lt} ; / \mathrm{em} \& \mathrm{gt} ;]$ catalyze the CO PROX reaction with high activity and selectivity at mild conditions. Sci. Adv. 6, eaba3809 (2020).

9. R. T. Hannagan, G. Giannakakis, R. Réocreux, J. Schumann, J. Finzel, Y. Wang, A. Michaelides, P. Deshlahra, P. Christopher, M. Flytzani-Stephanopoulos, M. Stamatakis, E. C. H. Sykes, Science (80-. )., in press, doi:10.1126/science.abg8389.

10. S. Sun, G. Sun, C. Pei, Z.-J. Zhao, J. Gong, Origin of Performances of Pt/Cu Single-Atom Alloy Catalysts for Propane Dehydrogenation. J. Phys. Chem. C (2021), doi:10.1021/acs.jpcc.1c04295.

11. Z. Chen, E. Vorobyeva, S. Mitchell, E. Fako, M. A. Ortuño, N. López, S. M. Collins, P. A. Midgley, S. Richard, G. Vilé, J. Pérez-Ramírez, A heterogeneous single-atom palladium catalyst surpassing homogeneous systems for Suzuki coupling. Nat. Nanotechnol. 13, 702-707 (2018).

12. L. Chen, R. R. Unocic, A. S. Hoffman, J. Hong, A. H. Braga, Z. Bao, S. R. Bare, J. Szanyi, Unlocking the Catalytic Potential of TiO2-Supported Pt Single Atoms for the Reverse Water-Gas Shift Reaction by Altering Their Chemical Environment. JACS Au. 1, 977-986 (2021).

13. Y. Chen, S. Ji, Y. Wang, J. Dong, W. Chen, Z. Li, R. Shen, L. Zheng, Z. Zhuang, D. Wang, Isolated Single Iron Atoms Anchored on N-Doped Porous Carbon as an Efficient Electrocatalyst for the Oxygen Reduction Reaction. Angew. Chem., Int. Ed. 56, 6937 (2017).

14. W. Zhong, R. Sa, L. Li, Y. He, L. Li, J. Bi, Z. Zhuang, Y. Yu, Z. Zou, A Covalent Organic Framework Bearing Single Ni Sites as a Synergistic Photocatalyst for Selective Photoreduction of CO2 to CO. J. Am. Chem. Soc. 141, 7615-7621 (2019).

15. C. Gao, S. Chen, Y. Wang, J. Wang, X. Zheng, J. Zhu, L. Song, W. Zhang, Y. Xiong, Heterogeneous Single-Atom Catalyst for Visible-Light-Driven High-Turnover CO2 Reduction: The Role of Electron Transfer. Adv. Mater. 30, 1704624 (2018).

16. Y. J. Sa, D.-J. Seo, J. Woo, J. T. Lim, J. Y. Cheon, S. Y. Yang, J. M. Lee, D. Kang, T. J. Shin, H. S. Shin, H. Y. Jeong, C. S. Kim, M. G. Kim, T.-Y. Kim, S. H. Joo, A General Approach to Preferential Formation of Active Fe-Nx Sites in Fe-N/C Electrocatalysts for Efficient Oxygen Reduction Reaction. J. Am. Chem. Soc. 138, 15046-15056 (2016).

17. K. Jiang, B. Liu, M. Luo, S. Ning, M. Peng, Y. Zhao, Y.-R. Lu, T.-S. Chan, F. M. F. de Groot, Y. Tan, Single platinum atoms embedded in nanoporous cobalt selenide as electrocatalyst for accelerating hydrogen evolution reaction. Nat. Commun. 10, 1743 (2019).

18. X. Ge, P. Zhou, Q. Zhang, Z. Xia, S. Chen, P. Gao, Z. Zhang, L. Gu, S. Guo, Palladium 
Single Atoms on TiO 2 as a Photocatalytic Sensing Platform for Analyzing the Organophosphorus Pesticide Chlorpyrifos. Angew. Chemie. 132, 238-242 (2020).

19. S. Sun, G. Zhang, N. Gauquelin, N. Chen, J. Zhou, S. Yang, W. Chen, X. Meng, D. Geng, M. N. Banis, R. Li, S. Ye, S. Knights, G. A. Botton, T.-K. Sham, X. Sun, Single-atom Catalysis Using Pt/Graphene Achieved through Atomic Layer Deposition. Sci. Rep. 3, 1775 (2013).

20. H. Wei, K. Huang, D. Wang, R. Zhang, B. Ge, J. Ma, B. Wen, S. Zhang, Q. Li, M. Lei, C. Zhang, J. Irawan, L.-M. Liu, H. Wu, Iced photochemical reduction to synthesize atomically dispersed metals by suppressing nanocrystal growth. Nat. Commun. 8, 1490 (2017).

21. Y. Yao, Z. Huang, P. Xie, L. Wu, L. Ma, T. Li, Z. Pang, M. Jiao, Z. Liang, J. Gao, Y. He, D. J. Kline, M. R. Zachariah, C. Wang, J. Lu, T. Wu, T. Li, C. Wang, R. ShahbazianYassar, L. Hu, High temperature shockwave stabilized single atoms. Nat. Nanotechnol. 14, 851-857 (2019).

22. H. Adabi, A. Shakouri, N. Ul Hassan, J. R. Varcoe, B. Zulevi, A. Serov, J. R. Regalbuto, W. E. Mustain, High-performing commercial Fe-N-C cathode electrocatalyst for anionexchange membrane fuel cells. Nat. Energy. 6, 834-843 (2021).

23. W. A. Spieker, J. Liu, X. Hao, J. T. Miller, A. J. Kropf, J. R. Regalbuto, An EXAFS study of the coordination chemistry of hydrogen hexachloroplatinate (IV): 2. Speciation of complexes adsorbed onto alumina. Appl. Catal. A Gen. 243, 53-66 (2003).

24. A. Wong, Q. Liu, S. Griffin, A. Nicholls, J. R. Regalbuto, Synthesis of ultrasmall, homogeneously alloyed, bimetallic nanoparticles on silica supports. Science (80-. ). 358, 1427-1430 (2017).

25. L. Jiao, J. R. Regalbuto, The synthesis of highly dispersed noble and base metals on silica via strong electrostatic adsorption: I. Amorphous silica. J. Catal. 260, 329-341 (2008).

26. S. Lambert, N. Job, L. D’Souza, M. F. R. Pereira, R. Pirard, B. Heinrichs, J. L. Figueiredo, J.-P. Pirard, J. R. Regalbuto, Synthesis of very highly dispersed platinum catalysts supported on carbon xerogels by the strong electrostatic adsorption method. $J$. Catal. 261, 23-33 (2009).

27. wen xiong, B. Mehrabadi, S. G. Karakalos, R. White, A. Shakouri, P. Kasak, S. J. Zaidi, J. Weidner, J. R. Regalbuto, H. R. Colon-Mercado, J. R. Monnier, Enhanced performance of oxygen-functionalized, multi-walled carbon nanotubes as support for Pt and Pt-Ru bimetallic catalysts for methanol electrooxidation. ACS Appl. Energy Mater. (2020), doi:10.1021/acsaem.0c00477.

28. B. A. T. Mehrabadi, R. White, A. Shakouri, J. R. Regalbuto, J. W. Weidner, J. R. Monnier, Ruthenium-platinum bimetallic catalysts with controlled surface compositions and enhanced performance for methanol oxidation. Catal. Today. 334 (2019), doi:10.1016/j.cattod.2018.11.042.

29. J. Resasco, P. Christopher, Atomically Dispersed Pt-group Catalysts: Reactivity, Uniformity, Structural Evolution, and Paths to Increased Functionality. J. Phys. Chem. Lett. 11, 10114-10123 (2020).

30. L. DeRita, S. Dai, K. Lopez-Zepeda, N. Pham, G. W. Graham, X. Pan, P. Christopher, 
Catalyst Architecture for Stable Single Atom Dispersion Enables Site-Specific Spectroscopic and Reactivity Measurements of CO Adsorbed to Pt Atoms, Oxidized Pt Clusters, and Metallic Pt Clusters on TiO2. J. Am. Chem. Soc. 139, 14150 (2017).

31. J. Zhang, C. Asokan, G. Zakem, P. Christopher, J. W. Medlin, Enhancing Sintering Resistance of Atomically Dispersed Catalysts in Reducing Environments with Organic Monolayers. Green Energy Environ. (2021), doi:https://doi.org/10.1016/j.gee.2021.01.022.

32. W. Chen, X. Luo, T. J. A. Slater, Y. Zhou, S. Ling, R. Bao, J. Alves Fernandes, J. Wang, Y. Shen, General synthesis of single atom electrocatalysts via a facile condensationcarbonization process. J. Mater. Chem. A. 8, 25959-25969 (2020).

33. X. Hai, S. Xi, S. Mitchell, K. Harrath, H. Xu, D. F. Akl, D. Kong, J. Li, Z. Li, T. Sun, H. Yang, Y. Cui, C. Su, X. Zhao, J. Li, J. Pérez-Ramírez, J. Lu, Scalable two-step annealing method for preparing ultra-high-density single-atom catalyst libraries. Nat. Nanotechnol. (2021), doi:10.1038/s41565-021-01022-y.

34. X. Sun, S. R. Dawson, T. E. Parmentier, G. Malta, T. E. Davies, Q. He, L. Lu, D. J. Morgan, N. Carthey, P. Johnston, S. A. Kondrat, S. J. Freakley, C. J. Kiely, G. J. Hutchings, Facile synthesis of precious-metal single-site catalysts using organic solvents. Nat. Chem. 12, 560-567 (2020).

35. M. Babucci, F. E. Sarac Oztuna, L. M. Debefve, A. Boubnov, S. R. Bare, B. C. Gates, U. Unal, A. Uzun, Atomically Dispersed Reduced Graphene Aerogel-Supported Iridium Catalyst with an Iridium Loading of 14.8 wt \%. ACS Catal. 9, 9905-9913 (2019).

36. M. S. Kumar, M. Schwidder, W. Grünert, A. Brückner, On the nature of different iron sites and their catalytic role in Fe-ZSM-5 DeNOx catalysts: new insights by a combined EPR and UV/VIS spectroscopic approach. J. Catal. 227, 384-397 (2004).

37. S. Haukka, E.-L. Lakomaa, T. Suntola, in Adsorption and its Applications in Industry and Environmental Protection, A. B. T.-S. in S. S. and C. Dąbrowski, Ed. (Elsevier, 1999; https://www.sciencedirect.com/science/article/pii/S0167299199805709), vol. 120, pp. 715-750.

38. N. Santhanam, T. A. Conforti, W. Spieker, J. R. Regalbuto, Nature of metal catalyst precursors adsorbed onto oxide supports. Catal. Today. 21, 141-156 (1994).

39. J. Regalbuto, Ed., Catalyst Preparation (CRC Press, 2016; https://www.taylorfrancis.com/books/9781420006506).

40. M. R. Mlahi, E. M. Afsah, A. Negm, M. M. Mostafa, Synthesis of 8-hydroxyquinolium chloroacetate and synthesis of complexes derived from 8-hydroxyquinoline, and characterization, density functional theory and biological studies. Appl. Organomet. Chem. 29, 200-208 (2015).

41. J. Martín, An overview on ligands of therapeutically interest. Pharm. Pharmacol. Int. J. 6 (2018), doi:10.15406/ppij.2018.06.00177.

42. Rohini, K. Paul, V. Luxami, 8-Hydroxyquinoline Fluorophore for Sensing of Metal Ions and Anions. Chem. Rec. n/a (2020), doi:https://doi.org/10.1002/tcr.202000082.

43. V. Prachayasittikul, V. Prachayasittikul, S. Prachayasittikul, S. Ruchirawat, 8Hydroxyquinolines: a review of their metal chelating properties and medicinal 
applications. Drug Des. Devel. Ther., 1157 (2013).

44. A. Sheikhmohammadi, S. M. Mohseni, R. khodadadi, M. Sardar, M. Abtahi, S. Mahdavi, H. Keramati, Z. Dahaghin, S. Rezaei, M. Almasian, M. Sarkhosh, M. Faraji, S. Nazari, Application of graphene oxide modified with 8-hydroxyquinoline for the adsorption of $\mathrm{Cr}$ (VI) from wastewater: Optimization, kinetic, thermodynamic and equilibrium studies. $J$. Mol. Liq. 233, 75-88 (2017).

45. W. Guo, X. Meng, Y. Liu, L. Ni, Z. Hu, R. Chen, M. Meng, Y. Wang, J. Han, M. Luo, Synthesis and application of 8-hydroxyquinoline modified magnetic mesoporous carbon for adsorption of multivariate metal ions from aqueous solutions. J. Ind. Eng. Chem. 21, 340-349 (2015).

46. E. A. Ferreiro, S. G. de Bussetti, A. K. Helmy, Sorption of 8-Hydroxyquinoline by Some Clays and Oxides. Clays Clay Miner. 36, 61-67 (1988).

47. A. J. Therrien, A. J. R. Hensley, M. D. Marcinkowski, R. Zhang, F. R. Lucci, B. Coughlin, A. C. Schilling, J.-S. McEwen, E. C. H. Sykes, An atomic-scale view of singlesite Pt catalysis for low-temperature CO oxidation. Nat. Catal. 1, 192-198 (2018).

48. H. Zhang, P. An, W. Zhou, B. Y. Guan, P. Zhang, J. Dong, X. W. (David) Lou, Dynamic traction of lattice-confined platinum atoms into mesoporous carbon matrix for hydrogen evolution reaction. Sci. Adv. 4, eaao6657 (2018).

49. B. K. Vu, M. B. Song, S.-A. Park, Y. Lee, I. Y. Ahn, Y.-W. Suh, D. J. Suh, W.-I. Kim, H.L. Koh, Y. G. Choi, E. W. Shin, Electronic density enrichment of Pt catalysts by coke in the propane dehydrogenation. Korean J. Chem. Eng. 28, 383-387 (2011).

50. M. Mahmoodinia, P.-O. Åstrand, D. Chen, Tuning the Electronic Properties of SingleAtom Pt Catalysts by Functionalization of the Carbon Support Material. J. Phys. Chem. C. 121, 20802-20812 (2017).

51. A. J. Garza, G. E. Scuseria, S. B. Khan, A. M. Asiri, Assessment of long-range corrected functionals for the prediction of non-linear optical properties of organic materials. Chem. Phys. Lett. 575, 122-125 (2013).

52. J. Hulva, M. Meier, R. Bliem, Z. Jakub, F. Kraushofer, M. Schmid, U. Diebold, C. Franchini, G. S. Parkinson, Science (80-. )., in press, doi:10.1126/science.abe5757.

53. K. K. Zborowski, M. Solá, J. Poater, L. M. Proniewicz, Aromatic properties of 8hydroxyquinoline and its metal complexes. Cent. Eur. J. Chem. 11, 655-663 (2013).

54. R. J. Warr, A. N. Westra, K. J. Bell, J. Chartres, R. Ellis, C. Tong, T. G. Simmance, A. Gadzhieva, A. J. Blake, P. A. Tasker, M. Schröder, Selective Extraction and Transport of the [PtCl6]2- Anion through Outer-Sphere Coordination Chemistry. Chem. - A Eur. J. 15, 4836-4850 (2009).

55. A. Uysal, W. Rock, B. Qiao, W. Bu, B. Lin, Two-Step Adsorption of PtCl62-Complexes at a Charged Langmuir Monolayer: Role of Hydration and Ion Correlations. J. Phys. Chem. C. 121, 25377-25383 (2017).

56. I. Carson, K. J. MacRuary, E. D. Doidge, R. J. Ellis, R. A. Grant, R. J. Gordon, J. B. Love, C. A. Morrison, G. S. Nichol, P. A. Tasker, A. M. Wilson, Anion Receptor Design: Exploiting Outer-Sphere Coordination Chemistry To Obtain High Selectivity for Chloridometalates over Chloride. Inorg. Chem. 54, 8685-8692 (2015). 
Acknowledgments: The authors are grateful to the Dean of College of Engineering and Computing at the University of South Carolina, Professor Hossein Haj-Hariri for facilitating characterizations for this work.

Author contributions: Abolfazl Shakouri ${ }^{\dagger}$ and Horie Adabi ${ }^{\dagger}$ contributed equally to this work and are joint first authors. They have the right to list their name as first author in their CV.

Conceptualization: AS, HA

Methodology: AS, HA

Investigation: AS, HA, KS

Visualization: AS, HA, CW, JR

Funding acquisition: JR, CW, WM

Project administration: AS, HA, JR, CW

Supervision: JR, CW, WM

Writing - original draft: AS, HA

Writing - review \& editing: AS, HA, JR, CW

Competing interests: The authors declare no conflicts of interest. The funders had no role in the design of the study, in the collection, analyses, or interpretation of data, in the writing of the 20 manuscript, or in the decision to publish the results.

US Patent App. 63/131,858, 2020, AS, HA, JR, CW, WM

Data and materials availability: The authors declare that all data are available in the main text or the supplementary materials.

\section{Supplementary Materials}

Materials and Methods

Supplementary Text

Figs. S1 to S9 